\title{
Type-Specific Identification of Genital Human Papillomavirus Infection in Women with Cytological Abnormality
}

\author{
Hernán Vargas $^{a} \quad$ Jenny P. Sánchez ${ }^{a} \quad$ Mónica L. Guerrero ${ }^{a} \quad$ Leider T. Ortiz $^{a}$ \\ Dayanne M. Rodríguez $^{a}$ Jairo Amaya ${ }^{b}$ Liliana P. Diaz $^{a} \quad$ Sandra L. Gómez $^{a}$ \\ Carlos Golijow ${ }^{\mathrm{c}}$ \\ a Laboratorio de Salud Pública, Dirección de Epidemiología, Análisis y Gestión de Políticas de Salud Colectiva, \\ Subsecretaria de Salud Pública, Secretaría Distrital de Salud, and ${ }^{\text {b}}$ Facultad de Medicina, Universidad Nacional de \\ Colombia, Hospital Engativá E.S.E., Bogotá, Colombia; ' IGEVET - Instituto de Genética Veterinaria 'Ing. Fernando \\ Dulout' (UNLP-CONICET), La Plata, Argentina
}

\section{Key Words}

Cytological abnormality · Cervical cancer $\cdot$ Human papillomavirus - Prevalence - Epidemiological profile .

Atypical squamous cells of undetermined significance

\begin{abstract}
Objectives: To estimate the frequency of human papillomavirus (HPV) infection and the genotype distribution of HPV among women with a Pap smear showing atypical squamous cells of undetermined significance (ASC-US) attending the Program for the Detection and Control of Cervical Cancer in Bogotá, Colombia. Study Design: Cervical samples from 200 women with an ASC-US Pap smear were analyzed for the presence of HPV DNA and genotype distribution using a commercial molecular technique (Linear Array ${ }^{\circledR}$; Roche Molecular Systems, USA). Results: HPV infection was found in 140 women (70\%). High-risk HPV types were present in $46.4 \%$ of the samples; $16.4 \%$ showed a low-risk HPV type, and $37.1 \%$ showed both. Of the positive samples, $42.9 \%$ were infected with a single viral genotype, whereas $57.1 \%$ exhibited multiple HPV infections. The most common HPV
\end{abstract}

genotypes were HPV 16, 53, and 52 with a prevalence of $26.4,16.4$, and $13.6 \%$, respectively. Conclusion: The epidemiological characterization of HPV infections described in this study might guide actions for epidemiological surveillance to strengthen the program in Bogotá and to develop appropriate HPV vaccination programs.

(C) 2016 S. Karger AG, Basel

\section{Introduction}

Cervical cancer is an important public health issue worldwide [1], representing the fourth most common cancer in women and the seventh overall, with an estimated 528,000 new cases in 2012 [2]. In this sense, Africa, Asia, and Central and South America account for $70 \%$ of the world cancer deaths [3].

In Colombia, the annual rate of cervical cancer is 18.2 cases per 100,000 women, making it one of the countries with the highest incidence of this type of cancer [4]. This is the reason why the Program for the Detection and Control of Cervical Cancer (PDCCC), implemented in a network

\section{KARGER}

E-Mail karger@karger.com www.karger.com/acy
(C) 2016 S. Karger AG, Basel

0001-5547/16/0603-0211\$39.50/0
Correspondence to: Dr. Hernán Vargas

Laboratorio de Salud Pública

Dirección de Epidemiología, Análisis y Gestión de Políticas de Salud Colectiva

Carrera 32 No 12-81, Bogotá 111611 (Colombia)

E-Mail hernan.vargas@yahoo.com 
of public hospitals in Bogotá, Colombia, uses cervical cytology screening for the early detection of abnormalities which may eventually progress to cancer. Although in the last 40 years this strategy has dramatically decreased the disease incidence and mortality worldwide [5], several studies have shown that this approach does not contribute to the timely management of cervical disease [6] since it does not detect the presence of human papillomavirus (HPV), a prerequisite for cervical carcinogenesis [7].

HPV is a common sexually transmitted virus [8] tightly associated with the development of cervical cancer. Genetic analysis of cervical carcinomas has revealed that nearly $99.7 \%$ of cervical squamous carcinomas contain DNA of this virus [6]. However, this relationship has been established only with certain viral genotypes, mainly HPV 16 and HPV 18, considered high-risk (HR) HPV types because of their oncogenic potential to cause proliferation of malignant cells in the cervical epithelium [4]. These 2 genotypes are responsible for $60-80 \%$ of all cervical cancers [9]. On the other hand, low-risk (LR) HPV types have been associated with the development of genital warts [10].

Basically, virus particles can enter the epithelium through microabrasions generated during sex [11]. The HPV cycle induces the proliferation of basal and parabasal cells, leading to the disruption of epithelial differentiation and generating changes in tissue structure and physiology, which contribute to the pathogenesis of cervical cancer [12]. Squamous abnormalities are identified through cervical cytology according to the Bethesda System (2014), and they comprise: atypical squamous cells (ASC), including ASC of undetermined significance (ASC-US), where ASC cannot exclude H-SIL; low-grade squamous intraepithelial lesions, including low-grade dysplasia; high-grade squamous intraepithelial lesions, including moderate and severe dysplasia (CIN II AND CIN III), and squamous cell carcinoma [13].

The ASC-US category involves the largest number of abnormal cytology reports [14], without establishing as such benign or malignant cellular changes. In fact, it highlights the factors that can lead to transient changes in cervical epithelium [15]. Consequently, there is no consensus on the inclusion of women with an ASC-US diagnosis in the program, leading to a risk of disease progression in this particular group of women. Current patient management guidelines recommend the use of HR HPV DNA testing as a triage method to identify women $\geq 21$ years old with ASC-US who are at an increased risk of cervical cancer and thus determine the need for referral for colposcopy exploration [16].
The aim of the present study was to determine the type-specific prevalence of HPV using the commercial molecular technique Linear Array ${ }^{\circledR}$ (Roche Molecular Systems, USA) in a set of 200 cervical cytology samples obtained from women with an ASC-US diagnosis belonging to the PDCCC of Bogotá.

\section{Materials and Methods}

The study population included 200 women with a cytological diagnosis of ASC-US enrolled into the PDCCC from a public hospital network in Engativá, a public hospital affiliated with the health system of Bogotá. Participants consulted the program between March and October 2014 and agreed to voluntarily participate in this study by providing informed consent. Patients between 17 and 63 years of age were included in this study. Information on sociodemographic characteristics, medical history, and sexual and reproductive behavior was obtained at the time of the gynecological visit. Pregnant women or women diagnosed with other cervical diseases were excluded. The management protocol of the participants is shown in figure 1 . This study was approved by the Ethics Committee of the Secretaría de Salud de Bogotá.

Collection of Cervical Samples and Personal Information

Prior to colposcopy, cervical samples were taken from each patient using a cytobrush and preserved in transport medium (COBAS ${ }^{\circledR}$ PCR Cell Collection Media; Roche Molecular Systems) following the manufacturer's instructions. The samples were stored at room temperature until processing at the Laboratory of Public Health, Bogotá.

\section{HPV Detection and Typing}

Type-specific identification of HPV genotypes was performed using the Linear Array technique (Roche Molecular Systems) according to the manufacturer's instructions. This technique allows the identification of $37 \mathrm{HPV}$ genotypes, including $14 \mathrm{HR}$ genotypes (i.e. $16,18,31,33,35,39,45,51,52,56,58,59,66$, and 68) and 23 LR viral types (i.e. 6, 11, 26, 40, 42, 53, 54, 55, 61, 62, 64, 67, 69, 70, 71, 72, 73, $81,82,83,84$, IS39, and CP6108), which are widely used in epidemiological studies. The Linear Array HPV test (Roche Molecular Systems) has $96 \%$ sensitivity and $99 \%$ specificity to detect DNA from HR HPV types (Linear Array HPV Genotyping Test ${ }^{\circledR}$; Roche). Extraction, amplification, and hybridization steps allow identification of both the target viral genetic material and a fragment of the human $\beta$-globin gene, used as the internal control in sample processing.

\section{Statistical Analysis}

The sample size was calculated considering the number of cytological samples analyzed during the year 2012 and the expected prevalence of $4 \%$ due to an ASC-US diagnosis. Accordingly, it included 160 samples (95\% reliability and 3\% error). However, since the number of samples collected during the sampling period was large, the sample size was increased to 200 specimens. The HPV frequency distribution was analyzed, with data collected in a database developed in Microsoft Excel ${ }^{\circledR}$. A bar graph showing single and multiple infections was created using the same software. Confidence intervals (CI) for the overall HPV prevalence and type-specific viral prevalences were calculated using Epi Info 3.5.1 software. 


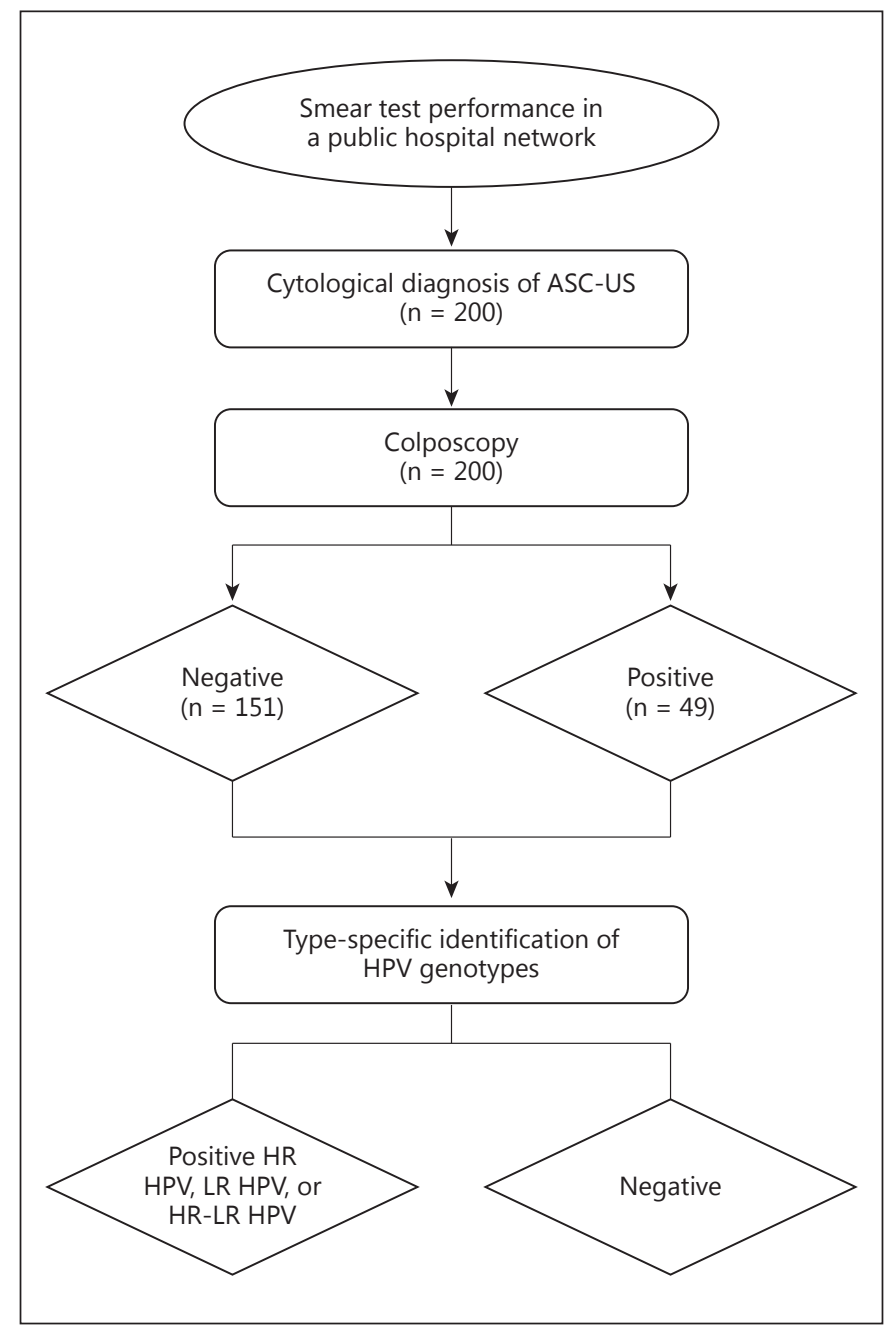

Fig. 1. Study protocol of patients with an ASC-US diagnosis enrolled into the PDCCC (Bogotá, 2014).

\section{Results}

A total of 200 women with an ASC-US diagnosis were included in this study (mean age $35.9 \pm 11.42$ years). The highest prevalence of ASC-US diagnosis was recorded among women aged 25-34 years (table 1). Briefly, 20.5\% (CI 15.26-26.89\%) of women with ASC-US were below 24 years of age, $27.5 \%$ (CI 21.55-34.33\%) were aged 2534 years, $24.5 \%$ (CI $18.83-31.16 \%$ ) were aged $35-44$ years, $22.5 \%$ (CI $17.03-29.04 \%$ ) were aged $45-54$ years, and $4.5 \%$ (CI 2.21-8.64\%) were over 55 years of age. Data were missing for 1 patient.

The molecular analysis demonstrated that all of the 200 samples were suitable for HPV detection and typing according to the results obtained via $\beta$-globin gene frag-

Genital HPV Infection in Women with

Cytological Abnormality
Table 1. HPV positivity distribution by age group in women with ASC-US

\begin{tabular}{llll}
\hline $\begin{array}{l}\text { Age group, } \\
\text { years }\end{array}$ & $\begin{array}{l}\text { Study population, } \\
\mathrm{n}(\%)\end{array}$ & \multicolumn{2}{l}{ HPV positivity } \\
\cline { 3 - 4 } & & $\mathrm{n}(\%)$ & $95 \% \mathrm{CI}$ \\
\hline$<24$ & $41(20.5)$ & $38(92.68)$ & $78.99-98.09$ \\
$25-34$ & $55(27.5)$ & $43(78.18)$ & $64.63-87.75$ \\
$35-44$ & $49(24.5)$ & $34(69.39)$ & $54.42-81.32$ \\
$45-54$ & $45(22.5)$ & $20(44.44)$ & $29.95-59.87$ \\
$>55$ & $9(4.5)$ & $5(55.56)$ & $22.65-84.65$ \\
Unknown & $1(0.5)$ & $0(0)$ & 0 \\
\hline
\end{tabular}

Women aged $<24$ years had the highest prevalence of viral infection.

ment amplification. Viral DNA analysis showed that 140 of the 200 women $(70.0 \%$, CI $63.45-76.55 \%)$ had HPV infection. Thirty-two different HPV genotypes were identified in the samples using this commercial molecular technique (fig. 2). Eighteen LR HPV types (HPV 53, 70, $84,42,61,54,62,81,6$, CP $6108,71,73$, IS39, 55, 72, 83, 67, and 69) and 14 HR genotypes (i.e. HPV 16, 52, 58, 59, $39,18,31,45,66,56,35,33,51$, and 68$)$ were identified among the ASC-US lesions. The most common HR HPV type was HPV 16, with a prevalence of $26.4 \%$ (CI 19.50 $34.66 \%)$, and HPV 52, 58, 59, 39, 18, 31, 45, 66, 56, 35, and 59 were the top 11 most commonly detected HPV genotypes in women with ASC-US (fig. 2). HPV 18 and 31 had the same low frequency (i.e. $7.9 \%$, CI 4.18-13.95\%). Moreover, the most commonly detected LR HPV genotypes were HPV 53, 70, 84, 42, and 61, with a prevalence of $17.1 \%$ (CI 10.90-23.84\%), 9.3\% (CI 5.23-15.66\%), 6.4\% (CI 3.16-12.20\%), and 5.7\% (CI 2.68-11.31\%) for the last 2 LR types, respectively. Surprisingly, the prevalence of HPV 6 was lower than 5\% and HPV 11 was not detected in the studied cervical samples.

Nearly $60 \%(n=81)$ of the patients positive for HPV infection were younger than 34 years and HPV positivity decreased with increasing age, with the highest prevalence appearing in women aged 25-34 years (table 1). About $60 \%(n=81)$ of the patients positive for HPV infection were younger than 34 years and HPV positivity decreased with increasing age, with the highest prevalence appearing in women aged 24 years or younger (table 1).

Molecular analysis showed that $42.9 \%$ (CI 35.79$50.01 \%)$ of the HPV-positive samples had single infections, whereas 57.1\% (CI 49.99-64.21\%) had multiple in- 


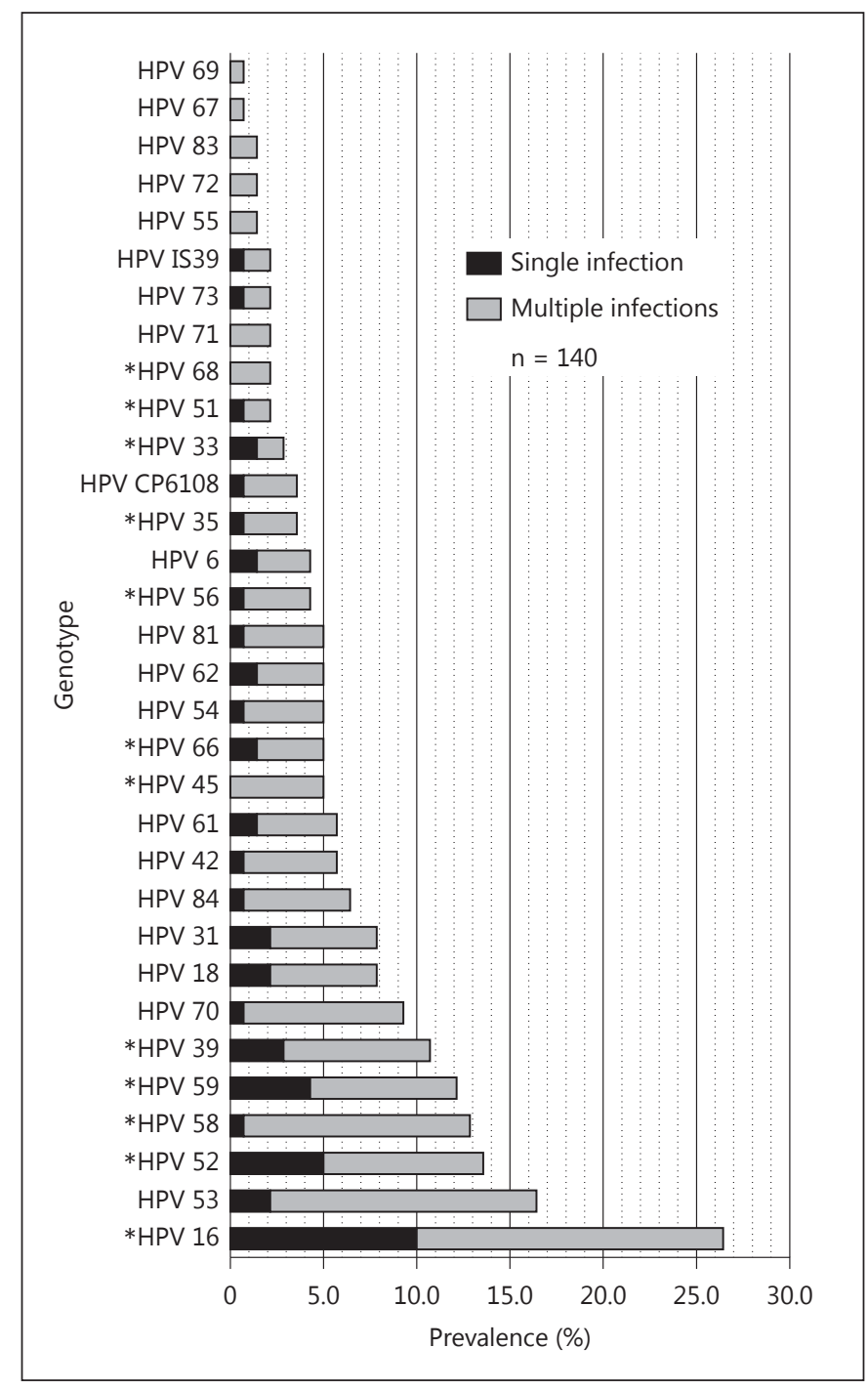

Fig. 2. Prevalence of HPV genotypes in women with ASC-US, categorized according to simple and multiple infections. * HR HPV types.

fections. The HPV 16 genotype most frequently presented as a single infection (10\% of the samples), followed by HPV 52 and HPV 59 (5.0 and 4.3\% of the analyzed cervical samples, respectively).

HPV 16 was the most prevalent genotype in all age groups, except for women over 55 years of age, in whom HPV 52 had the highest prevalence. It should be noted that the prevalence of HPV 16 and HPV 18 decreases with age. The prevalence of HPV 39 was higher in women between 25 and 34 years of age. Overall, almost the same HPV types were seen in women aged 24-44 years, when the dynamics of the infection dramatically changes (fig. 3).

\section{Discussion}

This study provides solid baseline information about the distribution of circulating HPV genotypes in women with a cytological diagnosis of ASC-US from Bogotá. Further, it is the first epidemiological HPV profile performed in women enrolled into the PDCCC.

In this study, $70 \%(140 / 200)$ of the population presented infection with at least 1 viral genotype. We identified 32 genotypes, i.e. $14 \mathrm{HR}$ and $18 \mathrm{LR} \mathrm{HPV} \mathrm{types.} \mathrm{A} \mathrm{high}$ diversity of HPV types was observed in women with a cytological diagnosis of ASC-US, especially younger women. However, as reported by Molano et al. [7], the viral heterogeneity of this particular cervical condition was no longer seen in severe dysplasia. Thirty percent $(60 / 200)$ of the women showed negative results for HPV genetic material, probably because the number of viral copies in the sample was below the detection limit of the technique, thus preventing the detection of HPV; maybe the patient's immune response favored the elimination or clearance of the virus $[9,12]$, because the cytological classification did not correspond to the initial diagnosis and those patients had cervical reactive changes generated by other causes.

Farfán-Vargas et al. [1], in a study of women with ASC-US from the city of Bogotá, reported an HPV prevalence of $20.5 \%$, much lower than that found in the present study (70\%). The prevalence of single and multiple infections found by those authors was 62.9 and $37.1 \%$, respectively, being inverted in relation to that found in this study, where single infections accounted for $42.9 \%$ of cases and multiple infections reached 57.1\%. Such discrepancy could be associated with the population's characteristics and the methodological design. In fact, the authors also included women diagnosed with low-grade squamous intraepithelial lesions, mostly belonging to secondary prevention programs for cervical cancer. Furthermore, those authors used the reverse line blot technique, whose sensitivity and specificity are different from those of the Linear Array technique implemented in the present study. As pointed out by other authors, evaluation of multiple infections has a high clinical impact since patients with multiple HPV types have increased susceptibility to the development of lesions of the uterine cervix [15].

Of the 140 patients infected with HPV, 83.5\% ( $\mathrm{n}=117)$ had HR HPV types and $16.5 \%(\mathrm{n}=23)$ had LR HPV genotypes. Although the prevalence and distribution of HPV genotypes vary greatly around the world, our data are similar to those reported by Delgado et al. [17]. That 
Fig. 3. HR HPV positivity in the different

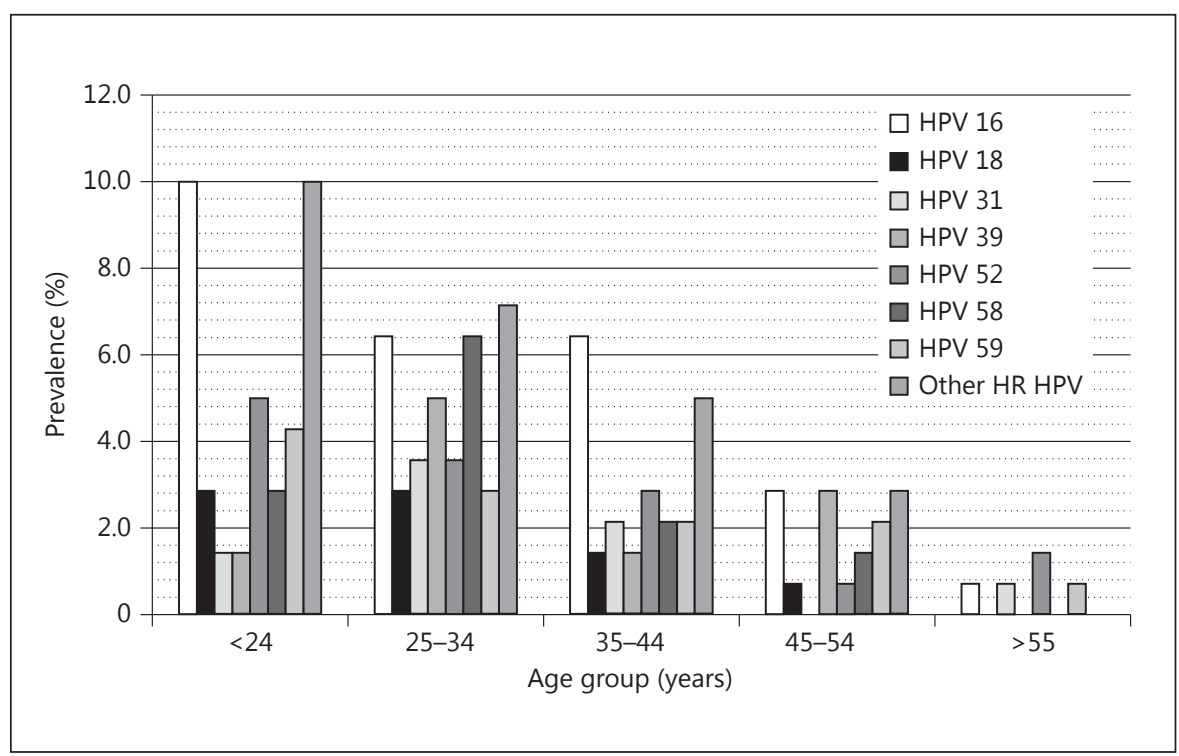
age groups.

group conducted an epidemiological study in Spanish women with an abnormal cytological diagnosis, using the same molecular identification system as ours. Delgado et al. [17] determined a prevalence of $94.3 \%$ for HR HPV types in Spanish women with a previous diagnosis of ASC-US. The reported HPV prevalences were similar to those found in this study. HPV 16 was also the most frequent viral type observed in the Spanish population (29.7\%), followed by HPV 53 (16\%), HPV 52 (12\%), and HPV 39 (10.8\%), showing extreme concordance with the prevalences found for these viral types in the present study. In contrast, HPV 18, 51, and 58 showed quite divergent prevalences. Martín et al. [18] also analyzed cervical samples from 2,461 women aged 15-75 years with cytological abnormalities in central Spain. The genotype most frequently found in the ASC-US category was HPV 16 (31\%), followed by HPV $53(16 \%)$ and HPV 31 (11\%); multiple infections were found in $36 \%$ of the analyzed samples, indicating that these HPV types shared prevalences in different geographical zones.

Epidemiological data pointed to HPV 58 as the second most prevalent HR type in South America, after HPV 16 [19]. That status is supported by the findings of this study, where HPV 52 and HPV 58 shared almost the same prevalence (i.e. 13.6 and $12.9 \%$, respectively). On the other hand, Dickson et al. [20] demonstrated an HPV 18 prevalence of $0.8 \%$ in US women diagnosed with ASC-US. While this prevalence was much lower than that found in the present study (7.9\%), the obtained data suggest that in patients with a cytological ASC-US diagnosis this ge-

Genital HPV Infection in Women with Cytological Abnormality notype is not as prevalent as other HR viral types. The high prevalence of HPV 52 and 58 found in the present study suggests a wide circulation of these HR genotypes in the general population, not covered by vaccines, thus becoming an important target for the implementation of these prophylactic measures.

The divergences in the type-specific prevalences reported, compared to other studies, may be due to differences in the techniques employed, and the sensitivity, specificity, and genotypes identified by each particular test. However, the dynamics of HPV infection are not constant and the diversity of women attending the program and their sexual and reproductive habits can significantly alter the dynamics of this specific viral infection.

Different studies $[10,17]$ have suggested that HPV infection is most common in young women and that the likelihood of infection decreases with increasing age. It has been proposed that this situation can be due to the concept that in women over 30 years of age the proportion of transient infections is decreased and they develop cell-mediated immunity against viral genotypes [12] or reach stability in terms of their sex partner, which generally occurs in old age [21]. However, these hypotheses have not been elucidated to date [22]. Furthermore, it has been proposed that transient infections are common in young women, whereas persistent infections are common in older ones [23]. However, to elucidate whether this pattern also occurs in the studied population, persistence and follow-up studies are required. 
The establishment of infections with HPV 16 and 18 in women with a cytological diagnosis of ASC-US increases the risk of progression to CIN II or III [24]. Therefore, it is essential to identify those women with ASC-US infected with these HPV types in order to prioritize their clinical management and to ensure complete adherence to prevention programs.

This study is the first approach to the epidemiological profile of a population with a cytological diagnosis of ASC-US enrolled into the PDCCC of a public hospital network in the city of Bogotá. A high prevalence of HPV infection was observed in the analyzed population, where HPV 16 had the highest incidence. The data obtained in this study can guide actions for epidemiological surveillance, contributing to strengthening of the program and outlining of vaccination strategies in order to cover the most prevalent HPV types circulating in the country.

\section{Acknowledgments}

The authors are grateful to the professionals from the PDCCC, the District Department of Health, and the research group from the Laboratory of Public Health in Bogotá. Thanks are also due to A. Di Maggio for editing of this paper.

\section{Disclosure Statement}

The authors declare that they have no competing interests.

\section{References}

1 Farfán-Vargas YA, García-Robayo DA, Arias Murillo Y, Morales OL, Isaza M, Aristizábal Gutiérrez FA: Genotipificación del virus de papiloma humano en mujeres con hallazgo citológico de lesión escamosa intraepitelial de bajo grado (LSIL) o de significado indeterminado (ASC-US) en Bogotá, Colombia. Rev Colomb Cienc Quim Farm 2010;39:42-54.

- 2 Ferlay J, Soerjomataram I, Dikshit R, Eser S, Mathers C, Rebelo M, Parkin DM, Forman D, Bray F: Cancer incidence and mortality worldwide: sources, methods and major patterns in GLOBOCAN 2012. Int J Cancer 2015; 136:E359-E386.

3 Bernard W, Stewart, Wild C: World Cancer Report 2014. Lyon, International Agency for Research on Cancer, World Health Organization, 2014.

4 Soto-De Leon S, Camargo M, Sanchez R, Munoz M, Perez-Prados A, Purroy A, et al: Distribution patterns of infection with multiple types of human papillomaviruses and their association with risk factors. PLoS One 2011; 6:e14705.

5 Chao TK, Ke FY, Liao YP, Wang HC, Yu CP, Lai HC: Triage of cervical cytological diagnoses of atypical squamous cells by DNA methylation of paired boxed gene 1 (PAX1). Diagn Cytopathol 2013;41:41-46.

6 Zhang S-K, Ci P-W, Velicer C, Kang L-N, Liu B, Cui J-F, et al: Comparison of HPV genotypes and viral load between different sites of genital tract: the significance for cervical cancer screening. Cancer Epidemiol 2014;38: 168-173.

7 Molano M, Posso H, Weiderpass E, Van den Brule A, Ronderos M, Franceschi S, et al: Prevalence and determinants of HPV infection among Colombian women with normal cytology. Br J Cancer 2002;87:324-333.
8 Faridi R, Zahra A, Khan K, Idrees M: Oncogenic potential of Human Papillomavirus. Virol J 2011;8:269.

-9 Carter JR, Ding Z, Rose BR: HPV infection and cervical disease: a review. Aust NZJ Obstet Gynaecol 2011;51:103-108.

10 Argyri E, Papaspyridakos S, Tsimplaki E, Michala L, Myriokefalitaki E, Papassideri I, et al: A cross sectional study of HPV type prevalence according to age and cytology. BMC Infect Dis 2013;13:53.

11 López A, Lizano M: Cáncer cervicouterino y el virus del papiloma humano: la historia que no termina. Cancerología 2006;1:31-55.

12 Venezuela RF, Kiguen AX, Frutos MC, Cuffini CG: Circulation of human papillomavirus (HPV) genotypes in women from Córdoba, Argentina, with squamous intraepithelial lesions. Rev Inst Med Trop São Paulo 2012;54: $11-16$.

13 Nayar R, Wilbur D: The Bethesda System for Reporting Cervical Cytology: Definitions, Criteria and Explanatory Notes. Cham, Springer, 2015, pp 103-192.

14 Wright TC, Stoler MH, Behrens CM, Apple R, Derion T, Wright TL: The ATHENA human papillomavirus study: design, methods, and baseline results. Am J Obstet Gynecol 2012; 206:46.e1-46.e11.

15 Barcelos ACM, Michelin MA, Adad SJ, Murta EFC: Atypical squamous cells of undetermined significance: Bethesda classification and association with human papillomavirus. Infect Dis Obstet Gynecol 2011;2011:904674.

-16 Arbyn M, Buntinx F, Van Ranst M, Paraskevaidis E, Martin-Hirsch P, Dillner J: Virologic versus cytologic triage of women with equivocal Pap smears: a meta-analysis of the accuracy to detect high-grade intraepithelial neoplasia. J Natl Cancer Inst 2004;96:280-293.
17 Delgado D, Marín JM, de Diego J, Guerra S, González B, Barrios JL, et al: Human papillomavirus (HPV) genotype distribution in women with abnormal cervical cytology in the Basque Country, Spain. Enferm Infecc Microbiol Clin 2012;30:230-235.

18 Martín P, Kilany L, García D, López-García AM, Martín-Azaña MJ, Abraira V, et al: $\mathrm{Hu}$ man papillomavirus genotype distribution in Madrid and correlation with cytological data. BMC Infect Dis 2011;11:316.

19 Shen Y, Gong J-M, Li Y-Q, Gong Y-M, Lei $\mathrm{D}-\mathrm{M}$, Cheng G-M, et al: Epidemiology and genotype distribution of human papillomavirus (HPV) in women of Henan Province, China. Clin Chim Acta 2013;415:297-301.

20 Dickson EL, Vogel RI, Geller MA, Downs LS: Cervical cytology and multiple type HPV infection: a study of 8,182 women ages 31-65. Gynecol Oncol 2014;133:405-408.

21 Núñez-Troconis J, Delgado M, González J, Mindiola R, Velásquez J, Conde B, et al: Prevalence and risk factors of human papillomavirus infection in asymptomatic women in a Venezuelan urban area. Invest Clin 2009;50: 203-212.

22 Spiryda LB, Brown J, Zhang H, Burgis JT: Delaying Pap test screening in the adolescent population: an evidence-based approach. J Pediatr Adolesc Gynecol 2014;27:3-5.

23 Sijvarger C, González J, Prieto A, Messmer A, Mallimaci M, Alonio V, et al: Epidemiología de la infección cervical por virus papiloma humano en Ushuaia, Argentina. Rev Argent Microbiol 2006;38:19-24.

24 Castle PE, Gage JC, Wheeler CM, Schiffman $\mathrm{M}$ : The clinical meaning of a cervical intraepithelial neoplasia grade 1 biopsy. Obstet Gynecol 2011;118:1222-1229. 